\title{
Conservative versus liberal oxygenation targets for mechanically ventilated patients: pilot multicentre randomised trial
}

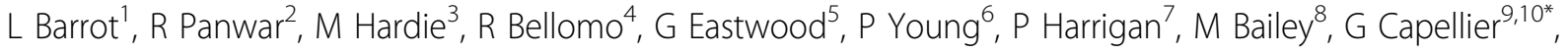 \\ CLOSE Study Investigators and the ANZICS Clinical Trials Group
}

From ESICM LIVES 2015

Berlin, Germany. 3-7 October 2015

\section{Introduction}

There is now increasing recognition of potential harm due to hyperoxia. Conventional practice of oxygen therapy often result in hyperoxia. Nearly all patients on mechanical ventilation receive supplemental oxygen therapy. However, RCTs investigating the effects of different oxygenation level during MV are lacking

\section{Objectives}

We aim to systematically evaluate whether liberal oxygenation strategy is beneficial or harmful compared to conservative oxygenation strategy for patients on invasive MV.

\section{Methods}

Patients likely to require 48 hours of MV, older than 18 years were included. Prospective trial conducted in 4 university affiliated ICU in Australia, New Zealand and France. Enrolled patients were randomly allocated to either liberal or conservative oxygenation $\operatorname{arm}(\mathrm{SaO} 2 / \mathrm{SpO} 2$ $>96 \%$ or between $88-92 \%$ respectively) and followed until day 90 . The bedside nurse titrated $\mathrm{FiO} 2$ to reach the oxygenation target.

\section{Results}

357 patients were screened and 104 were enrolled, 53 and 51 respectively in conservative and liberal arm respectively. Patients characteristics were similar at baseline. ABG's were checked more often in the conservative arm. Using an hypoxemia threshold of $\mathrm{SpO} 2<88 \%, 1 \%$ and $0.3 \%$ of the values in the conservative and liberal arm respectively were in hypoxemic range. With a $\mathrm{PaO} 2$ threshold $<55$

\footnotetext{
${ }^{9} \mathrm{CHRU}$ Besançon, Intensive Care Unit, Besançon, France

Full list of author information is available at the end of the article
}

$\mathrm{mmHg}, 7 \%$ and $1 \%$ respectively of the values were in hypoxemic range. With a threshold of $\mathrm{SpO} 2>98 \%$ while $\mathrm{FiO} 2>0.21,4 \%$ and $22 \%$ of $\mathrm{SpO} 2$ values respectively were in the hyperoxic range. Same difference were found when using an hyperoxic threshold of $\mathrm{PaO} 2>120 \mathrm{mmHg}(\mathrm{p}<$ 0.05 for all comparison). Participants spent majority of time within the intended target range in both groups. Mean AUC and 95\%CI for $\mathrm{SpO} 2, \mathrm{SaO} 2, \mathrm{PaO} 2$ and $\mathrm{FiO} 2$ were significantly lower in the conservative group compared to liberal group. Survival analysis curve were similar for both groups (OR 0.77 (95\%CI:0.4-1.50; $\mathrm{p}=0.44)$ ). For patients with a $\mathrm{P} / \mathrm{F}$ ratio $<300$, the separation in mean $\mathrm{FiO} 2$ was wider between the two arms. Outcome were similar. There slightly more arrhythmia-free days in the conservative arm. In thisP/F $<300$ subgroup, the adjusted hazard ratio for death by day 90 was lower in the conservative arm compared to liberal arm.

\section{Conclusions}

Our study demonstrate that conservative oxygenation strategy is a feasible and safe alternative to the usual liberal oxygenation strategy.

\section{Grant Acknowledgment}

Intensive Care Foundation (ANZ), University Hospital Besançon (France) and Don Du Souffle (France).

\footnotetext{
Authors' details

${ }^{1} \mathrm{CHRU}$ Besançon, Medical ICU, Besancon, France. ${ }^{2}$ John Hunter Hospital, Newcastle, Australia. ${ }^{3} J o h n$ Hunter Hospital, ICU, Newcastle, Australia. ${ }^{4}$ Austin Hospital, Department of Intensive Care, Melbourne, Australia. ${ }^{5}$ Austin Hospital, Intensive Care Unit, Melbourne, Australia. ${ }^{6}$ Wellington Hospital, Wellington, and Medical Research Institute of New Zealand, Intensive Care Unit, Wellington, New Zealand. ${ }^{7}$ John Hunter Hospital, Intensive Care Unit, Newcastle, Australia. ${ }^{8}$ Australian and New Zealand Intensive Care Research
} 
Centre, Department of Epidemiology and Preventive Medicine, Melbourne, Australia. ${ }^{9} \mathrm{CHRU}$ Besançon, Intensive Care Unit, Besançon, France. ${ }^{10}$ FrancheComté University, EA 3920, Besançon, France.

Published: 1 October 2015

\section{References}

1. Damiani E, Adrario E, Girardis M, Romano R, Pelaia P, Singer M, Donati A: Arterial hyperoxia and mortality in critically ill patients: a systematic review and meta-analysis. Crit Care 2014, 18(6):711.

2. Panwar R, Capellier G, Schmutz N, Davies A, Cooper DJ, Bailey M, et al: Current oxygenation practice in ventilated patients-an observational cohort study. Anaesth Intensive Care 2013, 41(4):505-514.

doi:10.1186/2197-425X-3-S1-A423

Cite this article as: Barrot et al:: Conservative versus liberal oxygenation targets for mechanically ventilated patients: pilot multicentre randomised trial. Intensive Care Medicine Experimental 2015 3(Suppl 1):A423.

\section{Submit your manuscript to a SpringerOpen ${ }^{\mathcal{O}}$ journal and benefit from:}

- Convenient online submission

- Rigorous peer review

- Immediate publication on acceptance

- Open access: articles freely available online

- High visibility within the field

- Retaining the copyright to your article 